\title{
Ressignificando o modelo físico: impressão 3D e ensino de projeto de arquitetura
}

\author{
A new meaning to the physical model: 3D printing and architectural design teaching \\ - Marcelo Tramontano \\ Nomads.usp - Instituto de Arquitetura e \\ Urbanismo, Universidade de São Paulo, Brasil \\ tramont@sc.usp.br \\ - Anibal Pereira Junior \\ Nomads.usp - Instituto de Arquitetura e \\ Urbanismo, Universidade de São Paulo, Brasil \\ pereirajunior590@gmail.com
}

\begin{abstract}
This article aims to produce reflections on two main aspects of the use of so-called 3D printing to produce physical models in architectural design processes: 1 . preparation of files, preparation of students; 2 . printed physical models as part of the design process. In addition to brief literature review of the key concepts involved, the article relies on results of research conducted by Nomads.usp Center of Interactive Living Studies (www.nomads.usp.br), and activities with students of the mandatory undergraduate course "Project 3: architecture, city, landscape," both of the Institute of Architecture and Urbanism, University of Sao Paulo, IAU-USP (www.iau.usp.br), Brazil.
\end{abstract}

Keywords: 3D Printing, Digital Fabrication, Architectural Design Teaching, Physical Models

\section{Introdução}

Este artigo tem como objetivo produzir reflexões sobre dois aspectos do emprego da chamada impressão 3D para produção de modelos físicos no processo de projeto de arquitetura: 1. preparação de arquivos, preparação de alunos; 2. modelos físicos impressos como parte do processo de projeto. Além de breve revisão bibliográfica dos principais conceitos envolvidos, o artigo apoia-se em resultados de pesquisas desenvolvidas pelo Nomads.usp Núcleo de Estudos de Habitares Interativos (www.nomads.usp.br), e em atividades realizadas com alunos da disciplina obrigatória de graduação "Projeto 3: Arquitetura, cidade, paisagem", ambos do Instituto de Arquitetura e Urbanismo da Universidade de São Paulo, IAU-USP (www.iau.usp.br).

A produção de modelos físicos arquitetônicos através da chamada impressão 3D vem atraindo o interesse de arquitetos e cursos de arquitetura, em todo o mundo, por permitir a rápida materialização de objetos arquitetônicos, sejam eles modelagens de terrenos, representações de edificações, de seus componentes ou de detalhes construtivos. Ela permite, também, que elementos assim representados sejam mais facilmente alterados, redesenhados e gerem novos modelos físicos que, por sua vez, possibilitem novas verificações e alterações. Processos digitais de produção de modelos físicos, incluindo a impressão 3D, têm sido associados a processos manuais e mecânicos tradicionais conferindo rigor dimensional e formal aos modelos. Detalhes complexos que, em modelos físicos tradicionais, demandariam tempo e habilidade, podem, assim, ser visualizados, estudados e alterados com certa rapidez com o auxílio da fabricação digital, em geral, e da impressão 3D, em particular.

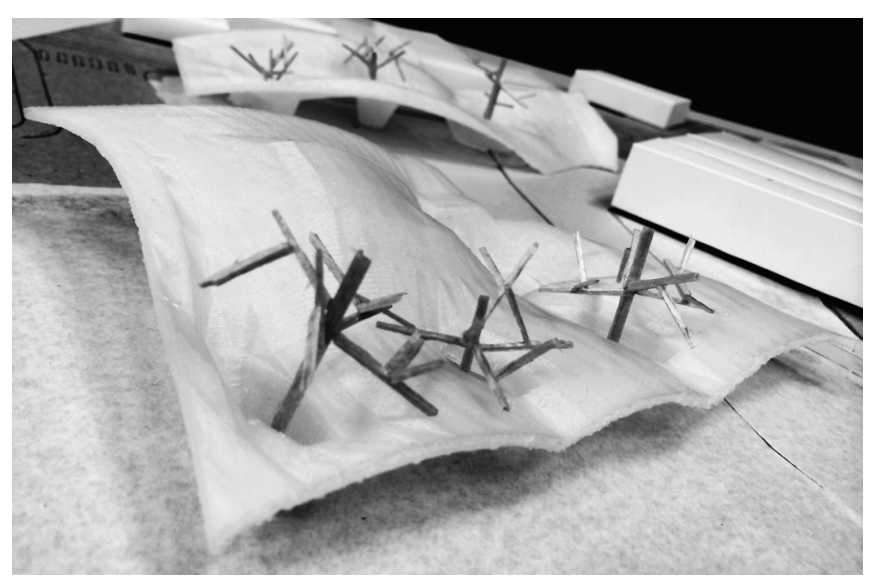

Figura 1: Modelo reduzido de volume com formas complexas produzido por impressão 3D, 2015. Fonte: M. Tramontano.

O que popularmente se costuma chamar de impressão 3D é uma técnica de fabricação digital que caracteriza-se pela produção de volumes físicos por adição de material. Uma 
impressora 3D age, efetivamente, de maneira análoga à de uma impressora gráfica comum, a qual deposita sobre o papel uma camada de tinta segundo as instruções que recebe advindas de um arquivo digital. A impressora 3D também deposita material por camadas, mas vai sobrepondo-as umas sobre as outras, conformando gradativamente um objeto tridimensional. O material depositado pelas impressoras utilizadas nas experiências abordadas nesse artigo pode ser de dois tipos: PLA (ácido polilático, ou poli lactato) ou ABS (acrilonitrila butadieno estireno), ambos em forma de filamento. Eles têm comportamentos distintos, que os tornam, respectivamente, mais apropriados para determinadas aplicações. O ABS é um polímero termoplástico produzido à base de petróleo, enquanto o PLA é um biopolímero (LIMA et al, 2009), o que significa que, em princípio, é um material biodegradável, pois é produzido a partir de fontes renováveis, como o amido de milho. O ABS é mais resistente e mais flexível que o PLA, sendo preferido para peças que solicitam esforços. Requer mais cuidados na impressão, como o aquecimento da mesa de impressão, para facilitar a retirada da peça impressa mas por outro lado, requer também que se aumente a rugosidade da superfície da mesa para melhorar a aderência da peça durante a impressão. Esses cuidados não são necessários com o PLA, que tem boa aderência à mesa de impressão durante o processo e pode ser retirado com relativa facilidade, dependendo da área de contato entre a peça e a mesa.

O processo de deposição de material por camadas utilizado por essas impressoras é conhecido como FDM, sigla do inglês Fused Deposition Modeling, ou Modelagem por Deposição Fundida (tradução nossa). Nele, as camadas são construídas sequencialmente por adição do filamento fundido, gerando a peça física, a partir da base até o topo, segundo camadas digitais definidas na etapa de fatiamento do modelo digital, informadas à impressora pelo arquivo do projeto. É importante que os alunos entendam esse processo e aprendam a operar a impressora porque, apesar de contar com máquinas de grande porte, a fabricação em escala industrial realiza-se segundo processos semelhantes. Tal compreensão permite antever problemas ou potencialidades do desenho proposto que podem revelar-se na fase de produção dos componentes construtivos. Sejam de código aberto (RepRap) ou fechado, essas pequenas impressoras têm, portanto ressignificado o papel da produção de modelos físicos nos processos de projeto de arquitetura e urbanismo, inclusive pela facilidade de sua manipulação e transporte, e também pelo baixo custo do investimento inicial e dos materiais utilizados.

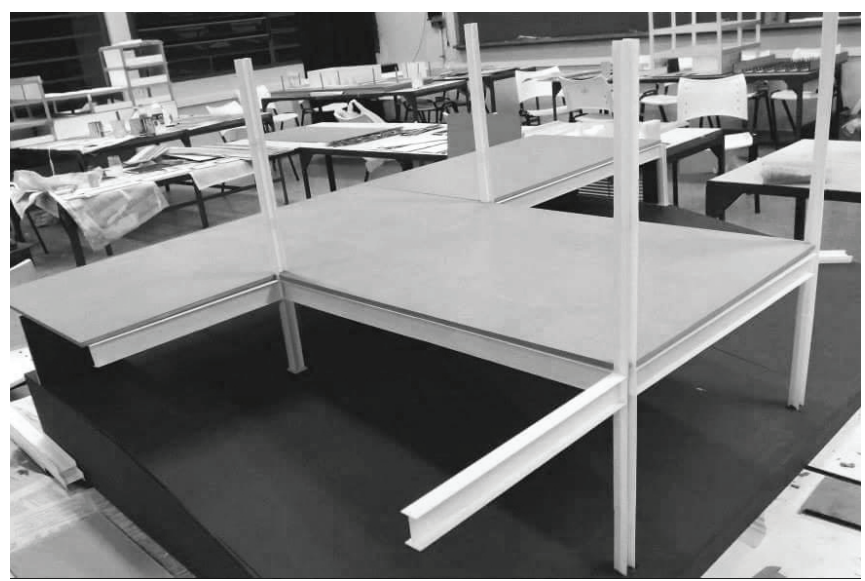

Figura 2: Maquete 1:20 de estrutura de perfís de aço impressos em 3D, 2014. Fonte: M. Tramontano.

\section{Preparação de arquivos, preparação de alunos}

Se, por um lado, busca-se sedimentar, nos alunos, o entendimento desse processo de fabricação digital, incentivando-os a operar as máquinas, por outro lado, é necessário incluir, dentre os assuntos tratados no atelier de projeto, alguns procedimentos técnicos referentes à preparação dos arquivos gráficos e à operação das impressoras. São informações simples, que podem ser facilmente assimiladas, mas que, por sua natureza, significam uma ampliação do espaço ocupado pela informática - ou, em outras palavras, da necessidade de manuseio de software e hardware - dentre os conhecimentos exigidos para a produção de projetos de arquitetura. Nesse sentido, apesar de mais difíceis de operar, as impressoras de código aberto podem apresentar um interesse maior na medida em que permitem a visualização e manipulação de uma grande quantidade de variáveis na configuração da impressão, semelhantemente às impressoras industriais de grande porte.

Um exemplo simples disso é o que se costuma chamar de geração do G-code, ou geração do código computacional que, basicamente, lê o volume a ser produzido e o representa como um conjunto de finíssimas camadas (ou fatias, donde o termo fatiamento para designar essa operação) sobrepostas, estruturando o conjunto de informações de que a impressora precisa para realizar cada camada. Esse conjunto de informações contém, ainda, diversas outras instruções para a produção, como, por exemplo, o ponto por onde a impressão da peça será iniciada, a quantidade de material a ser utilizada, a velocidade de impressão, a geração ou não de suporte e seu desenho, a forma e a quantidade de preenchimento das 
espessuras, entre outros. Embora os programas dasimpressoras costumem automatizar essa função, é interessante que os alunos entendam a operação para, posteriormente, conseguirem entender a razão de alguns eventuais erros de impressão relativamente comuns.

Um roteiro do tipo passo-a-passo sobre a produção de modelos impressos em 3D foi especialmente criado para a capacitação dos alunos da disciplina de Projeto 3. Nele, destacam-se: a) o processo de exportação a partir do programa Rhinoceros, considerando as configurações para exportação de arquivos em formato .stl. Além de ser um dos programas utilizados para projeto na disciplina, o Rhinoceros é bastante conveniente nessa fase de preparação pois possui ferramentas que fazem um mapeamento do modelo digital e indicam eventuais correções necessárias para a exportação do arquivo; b) a instalação e configuração de programas necessários para a impressão, que geram o código computacional G-code; e c) os procedimentos para operar a impressora 3D e lidar com suas configurações próprias, mas também para retirar o modelo impresso da mesa de impressão, realizar a limpeza da mesa e para garantir a segurança durante o processo.

No caso das impressoras que utilizam o sistema FDM com filamento de ABS, é preciso, com frequência, ajustar as configurações para que não ocorram problemas durante a impressão, como casos em que a peça se descola da base antes de ser finalizada ou em que algum tipo de má leitura do arquivo, durante a impressão, provoca erros ou mesmo a perda da peça impressa. Nas sessões de capacitação dos alunos, foram também abordadas questões operacionais, como o que fazer no caso de ocorrerem certos problemas durante a impressão, como cancelar uma impressão em caso de erro de leitura da máquina, como substituir o filamento, como desmontar e montar o cabeçote extrusor em caso de seu entupimento com resíduos de filamento, entre outros.

\section{Modelos físicos impressos como parte do processo de projeto}

As possibilidades abertas pela introdução das técnicas de fabricação digital no ensino de projeto em Arquitetura trazem de volta o modelo físico ao centro desse processo. De fato, nas últimas décadas, com a introdução e a rápida evolução da modelagem em ambiente digital, alunos e professores pareciam vir perguntando-se em quais aspectos do projeto e do processo de concepção o modelo físico aportava contribuições não contempladas pelo modelo digital. Em modelos digitais, é possível promover alterações rapidamente, estudar suas ambiências em diferentes momentos do dia e da noite, produzir avaliações técnicas com o auxílio de plugins diversos, e, através de animações, é possível caminhar no interior das edificações projetadas, antecipando experiências espaciais e evidenciando problemas diversos.

No entanto, conforme expõe Tramontano (2015):

"a modelagem física, em todas as suas fases de desenho dos componentes, preparação para fabricação, produção e montagem, curiosamente antecipa, às vezes com grande acuidade, questões produtivas, construtivas e de organização de obra que, em processos convencionais, tendem a revelarse apenas quando finalizada a concepção. De fato, existe um correlato claro entre as maneiras de produção dos componentes de modelos, através de máquinas controladas digitalmente (CNC, da sigla em inglês Computer Numeric Control) de corte a laser, impressão 3D e fresagem, e processos industriais baseados no uso de máquinas que trabalham de maneira bastante similar a essas, ainda que em outra escala.É, também porisso, fundamental que, na produção de seus modelos, cada aluno seja capacitado a manusear pessoalmente essas máquinas, pois isso vai ajudá-lo a construir um entendimento mais claro sobre a produção de componentes construtivos, futuramente, no âmbito da produção e da obra. Essa compreensão é essencial para que [...] os alunos sejam sensibilizados a preocupar-se com a viabilização técnica de suas proposições - que, hoje, ainda se situam no campo da novidade - agora auxiliados pela informatização dos processos de design e fabricação (DUNN, 2012)."

No caso da impressão 3D, a antecipação de procedimentos industriais de fabricação pode dizer respeito à produção de componentes com formas bastante complexas, cujos modelos físicos dificilmente poderiam ser produzidos, através de procedimentos mecânicos ou manuais, com a rapidez, o baixo custo e o rigor necessário para dar suporte a tomadas de decisão no processo de projeto. Por isso, ao lado de modelos reduzidos de perfís metálicos, cujas espessuras e necessidade de rigidez dificilmente seriam atingidas em processos manuais, os alunos da disciplina de Projeto 3 desenharam e produziram protótipos (VOLPATO et al, 2007) de peças de fixação ou ligações, podendo, assim, manusear e perceber-se como potenciais propositores e designers de componentes complexos para a indústria da construção.

Diferentes soluções técnico-construtivas para um mesmo problema puderam, assim, ser comparadas com relativa facilidade, permitindo que os alunos vislumbrassem a noção de file-to-factory, enunciada por Oosterhuis et al. (2004), de que os arquivos produzidos na fase de concepção podem, eles próprios, serem usados para informar as máquinas que executarão os componentes construtivos na indústria. Para essa compreensão, a passagem intermediária pela fabricação digital do modelo físico dos componentes é fundamental.

\section{Procedimentos metodológicos}

Os procedimentos metodológicos aqui apresentados referem-se à pesquisa de exploração das potencialidades da impressão 3D utilizando-se impressoras de pequeno porte, visando sua introdução em disciplinas de projeto de arquitetura. A pesquisa vem sendo realizada pelo Nomads. usp, e parte de seus resultados têm sido aplicados no âmbito da disciplina obrigatória de projeto de arquitetura "Projeto 3: Arquitetura, cidade, paisagem", no curso de graduação do IAU-USP. Busca-se, assim, avaliar as vantagens e limites da inserção da tecnologia de impressão 3D por FDM no processo de ensino de projeto. 
No caso proposto, a exploração das potencialidades e limites das impressoras se fez concomitantemente à revisão bibliográfica, seguindo sub-etapas de construção de modelos geométricos e exame dos arquivos digitais gerados a partir deles, através de diferentes programas computacionais paramétricos, produzindo um registro de todas as operações necessárias e relevantes do processo. Esse registro e a avaliação das experimentações embasaram a redação do roteiro do tipo passo-a-passo, já mencionado, para transferência da tecnologia aos alunos da disciplina, incluindo a capacitação dos alunos na geração de arquivos para impressão e no manuseio das impressoras. Tanto a capacitação quanto a montagem dos modelos físicos, pelos alunos, usando os elementos impressos, foram acompanhados pelos pesquisadores, que também produziram registros em foto, video, anotações e salvaguarda de metadados das impressões.

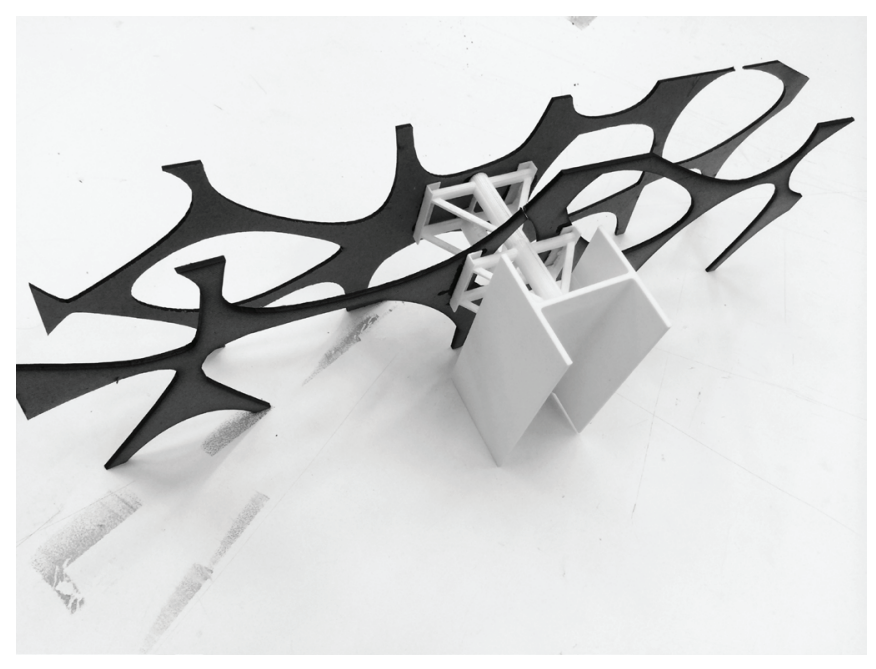

Figura 3: Modelo reduzido parcial de dispositivo de proteção solar produzido por corte a laser e impressão3D, 2014. Fonte: M. Tramontano.

Tais registros foram organizados e sistematizados a fim de também constituir a documentação dessa atividade prática na disciplina, visando a avaliação do processo junto aos alunos, professores e monitores, e pesquisadores do grupo de pesquisa. A avaliação estruturou-se segundo as etapas clássicas de coleta, sistematização, análise, síntese e conclusões preliminares, e seus resultados foram comparados a informações obtidas na bibliografia sobre o assunto e em pesquisas consolidadas, com o intuito de embasar e ampliar as conclusões finais.

\section{Resultados}

Desde o ano de 2014, modelos físicos impressos em 3D têm sido produzidos pelos alunos da disciplina de Projeto 3, no IAU-USP. Superados os desafios iniciais da capacitação para produção de arquivos e uso das impressoras, foi possível iniciar uma segunda etapa de trabalho, que inclui reflexões sobre o uso desses modelos no processo de projeto e sobre as reais contribuições da introdução dessa tecnologia de modelagem física na disciplina.

Algumas das principais contribuições percebidas, do uso de impressões 3D no processo de projeto de arquitetura, são: 1. a possibilidade de se representar rapidamente, em modelos físicos, arquiteturas de formas complexas, com precisão dimensional, 2. o estímulo ao desenvolvimento de detalhes construtivos como nós estruturais específicos e elementos de formas complexas, muitas vezes evitados pelos alunos em razão da dificuldade de sua visualização, e 3. a ampliação das possibilidades de criação de elementos com design exclusivo, não disponíveis, portanto, no mercado da construção mas que podem, eventualmente, ser produzidos através de técnicas de fabricação digital.

Na disciplina de Projeto 3 do IAU-USP, a impressão 3D tem sido também utilizada em associação com outras técnicas de fabricação digital, permitindo a modelagem física de detalhes construtivos envolvendo interfaces de diferentes componentes, durante a fase de concepção do projeto. Por exemplo, elementos de proteção solar de fachadas tiveram suas placas cortadas a laser e suas fixações impressas em 3D, para estudo das ligações entre elas e do conjunto com a fachada do edifício. Também têm sido produzidos ensaios comparativos entre testes com modelos digitais, usando programas de análise de insolação, por exemplo, cujos resultados são comparados com testes produzidos no heliodon com modelos físicos.

Dentre as dificuldades enfrentadas no processo, três pareceram principais. A primeira diz respeito ao tempo de impressão, muitas vezes extremamente longo, em função da complexidade formal da peça, ou do número de peças impressas necessárias, ou das dimensões da peça, ou, ainda, de uma combinação entre esses fatores. Além da duração da impressão propriamente dita, é preciso considerar o tempo - relativamente curto, mas difícil de prever por depender de cada caso - de preparação dos arquivos, sua conversão para .stl, etc.. Ainda assim, na avaliação dos alunos, professores e pesquisadores envolvidos, o uso da impressão 3D foi entendido como fundamental e sua contribuição, positiva tanto para o processo de projeto como para o resultado final. Na mesma avaliação, foi também corretamente argumentado que modelos com o grau de precisão e detalhamento como os que foram produzidos, e com formas difíceis de serem produzidas através de outras técnicas, demandariam muito mais tempo se produzidos de outra maneira, ou, em alguns casos, nem poderiam ter sido fabricados.

A segunda dificuldade enfrentada pelos alunos foi a constatação da necessidade de adequar os projetos a algumas limitações da máquina. Por exemplo, os limites dimensionais da área de impressão eram, às vezes, menores do que as medidas requeridas para os modelos a serem impressos. Isso fez com que os alunos elaborassem uma análise dos modelos digitais, dividindo-os em partes a serem impressas nas medidas corretas. Essa limitação dimensional e a reorganização que ela demanda podem ser exploradas com benefícios para o estudo do próprio projeto se, ao invés de uma simples divisão 
em partes, os modelos forem segmentados segundo seus componentes, ou segundo sua lógica construtiva, permitindo não apenas a adequação às dimensões da mesa de impressão mas também uma antevisão da montagem das diversas partes na obra.

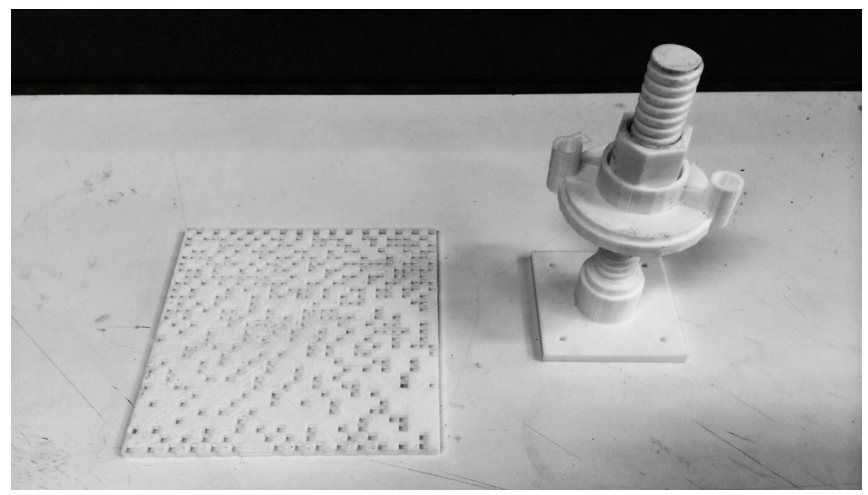

Figura 4: Modelos 1:1 de peças de ligação, 2014. Fonte: M. Tramontano.

A terceira dificuldade foi a geração de suportes para sustentação de algumas peças sobre a mesa de impressão, definidos automaticamente pelo programa que gera o G-code, em função da forma da peça. Esses suportes podem ser difíceis de remover, sendo necessário, em alguns casos, o uso de lixas e ferramentas especificas para sua remoção e posterior limpeza da peça. Diante disso, os alunos usaram o próprio programa de impressão para analisar o modelo antes da impressão, examinando as várias possibilidades de posicionamento do modelo na mesa para que o programa gerasse a menor quantidade possível de suportes, facilitando sua remoção, limpeza e montagem.

\section{Discussão}

Os dois aspectos selecionados para a construção desse artigo abrem um amplo leque de questões para debate, dentro da área de Arquitetura e Urbanismo. Permitem repensar desde o significado e o papel de modelos físicos no processo de projeto de arquitetura e urbanismo, até o conjunto de atividades que, efetivamente, a introdução dessa estratégia em disciplinas de projeto pressupõe. Expandem, também, o debate para a emergência de novos modos de produção industrial de elementos construtivos que se utilizam de equipamentos digitais, e que podem ser antecipados na produção de modelos através de tecnologias similares àquelas encontradas na indústria, ainda que em outra escala. Permitem, portanto, trazer para o atelier de projeto dos cursos de graduação um contato estreito com a produção física dos edifícios ali projetados, o que constitui uma novidade em termos de compreensão holística da produção física, em canteiro, das edificações desenhadas na escola.

Essas questões são potencializadas quando se trata de formas geométricas complexas, em geral pouco familiares para os alunos, ainda que permaneçam válidas para a

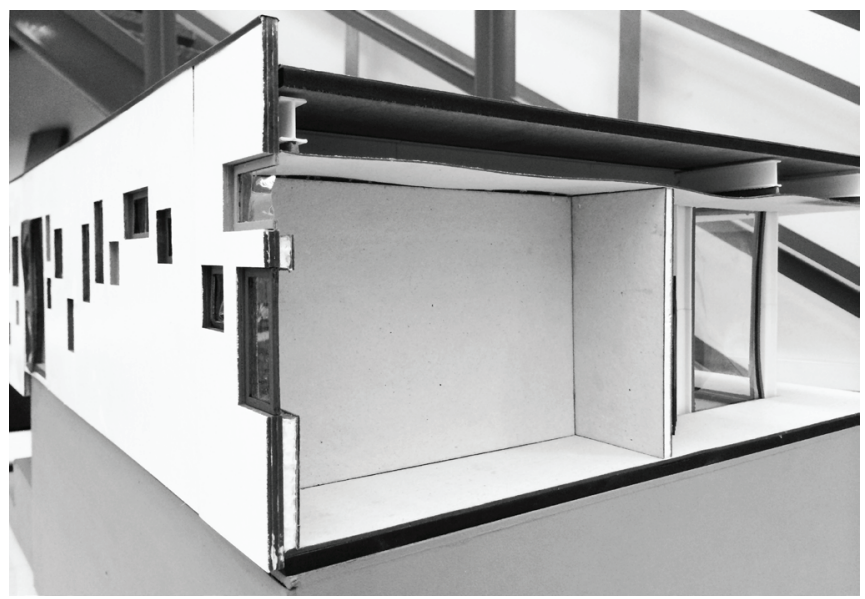

Figura 5: Maquete 1:20 com corte do sistema construtivo, produzida por corte a laser e impressão 3D, 2014. Fonte: M. Tramontano.

construção convencional que lida com elementos préfabricados e industrializados. Além disso, pôde ser verificado no IAU-USP o interesse de professores de outras disciplinas do curso de graduação, além de projeto, pelo uso das tecnologias digitais de produção de modelos físicos, como as disciplinas de história, dada sua dificuldade em promover a visualização de certos elementos construtivos pouco presentes na arquitetura atual.

Finalmente, a pesquisa aqui apresentada permite que nos indaguemos, enquanto pesquisadores brasileiros, sobre os usos das tecnologias digitais de produção de modelos físicos e elementos construtivos que melhor nos convêm, dadas nossa história, nosso estágio de desenvolvimento construtivo, e as visões sobre arquitetura de nossas sociedades e nossos profissionais.

\section{Referências}

Dunn, N. (2012). Digital fabrication in architecture. London: Laurence King.

Kowaltowski, C. C. K. D. et al. (2011). O processo de projeto em arquitetura da teoria à tecnologia. São Paulo. Oficina de Textos.

Lima G. L. et al. (2009). Revisão da aplicação de produtos biopolímeros obtidos pela reciclagem de plásticos em design. p.1-16 Disponível em: <http://www.ehu.eus/reviberpol/pdf/ SEP09/lima.pdf> Acesso: 10/09/2015.

Oosterhuis, K. et al. (2004). File to Factory and Real Time Behavior in ONL-Architecture. Proceedings of the 23rd Annual Conference of the Association for Computer Aided Design in Architecture and the 2004 Conference of the AIA Technology in Architectural Practice Knowledge Community. Cambridge, November 8-14.

Tramontano, M. (2015). Quando pesquisa e ensino se conectam: design paramétrico, fabricação digital e projeto de arquitetura. Anais Sigradi 2015. Florianópolis: Sigradi.

Volpato, N. et al. (2007). Prototipagem rápida: tecnologias e aplicações. São Paulo: Edgard Blücher. 